Tohoku J. Exp. Med., 2009, 218, 49-55

\title{
Accumulation of Macrophages Expressing Myeloid-Related Protein 8 Associated with the Progression of Sclerotic Changes in Children with IgA Nephropathy
}

\author{
Yukihiko Kawasaki, ${ }^{1}$ Kazuhide Suyama, ${ }^{1}$ Hayato Go, ${ }^{1}$ Takashi Imamura, \\ Yumiko Ushijima, ${ }^{1}$ Nobuko Sakai, ${ }^{1}$ Koichi Hashimoto ${ }^{1}$ and Mitsuaki Hosoya ${ }^{1}$ \\ ${ }^{1}$ Department of Pediatrics, Fukushima Medical University School of Medicine, Fukushima, Japan
}

\begin{abstract}
Myeloid-related protein (MRP) 8 is a calcium-binding protein of the S100 family. The renal accumulation of macrophages expressing MRP8 is associated with the inflammatory activity of glomerulonephritis. We evaluated the renal accumulation of macrophages expressing MRP8 in children with IgA nephropathy (IgAN). We collected data on 25 IgAN children who had been treated with prednisolone and divided these patients into two groups: Favorable group, consisting of 11 patients with normal urine and 6 with minor urinary abnormalities at $4.3 \pm 1.3$ years after initial treatment; and Unfavorable group, consisting of 8 patients with persistent nephropathy. The pathological renal findings were compared between both groups. The second biopsy was performed at two years after first biopsy at $5.5 \pm 4.9$ months from onset. In Favorable group, the glomerular accumulation of macrophages expressing MRP8, and mesangial cells expressing $\alpha$-smooth muscle actin ( $\alpha$-SMA) were lower in the second biopsy specimens than those of the first biopsy specimens. In Unfavorable group, the glomerular accumulation of macrophages expressing MRP8 detected in the second biopsy specimens was similar to that of the first biopsy, while the number of mesangial cells expressing $\alpha$-SMA and the index of renal sclerosis were higher in the second biopsy than in the first biopsy. The indexes of renal sclerosis were higher in children with more macrophages expressing MRP8 than in children with less macrophages expressing MRP8. Our results suggest that renal macrophages expressing MRP8 may be involved in the progression of sclerotic changes in children with IgAN - myeloid-related protein 8; myeloid-related protein 14; IgA nephropathy; $\alpha$-smooth muscle actin; prognosis.
\end{abstract}

Tohoku J. Exp. Med., 2009, 218 (1), 49-55. 두 2009 Tohoku University Medical Press

Immunoglobulin A nephropathy (IgAN) is the most common variety of primary glomerulonephritis in the world today. It was initially considered a benigen disease with a favorable prognosis, but then data from long-term follow-up studies revealed that the disease progressed to renal failure in 10 to $15 \%$ of patients in childhood. (Berger and Hinglais 1968; Droz 1976; Hogg et al. 1994; Chida et al. 1985).

Clinical predictors of a poor outcome include renal insufficiency, heavier degrees of proteinuria, and hypertension, while pathologic features of a poor prognosis include glomerular sclerosis, interstitial fibrosis and tubular atrophy (Hogg et al. 1994; Nagata et al. 1995).

Glomerular and interstitial macrophage accumulation has been described as a risk factor for the progression of most types of human glomerulonephritis, and a correlation between macrophages in interstitial lesions and renal dysfunction and histological damage, leading to renal injury, has been found (Nagata et al. 1995). Thus, macrophages play an important role in determining the outcome of chronic glomerulonephritis, including IgAN. Recently, many reports have discussed subclasses of macrophages expressing myeloid-related protein (MRP) 8 (S100A8) and MRP14 (S100A9), which are members of the S100 family (Zwadlo et al. 1985; Odink et al. 1987; Hisano et al. 2001; Frosch et al. 2004). MRP8 and MRP14 represent the predominant calcium-binding capacity of monocytes and neutrophils in their early stage of differentiation, but neither protein has been detected in resting tissue macrophages or in lymphocytes (Zwadlo et al. 1985; Odink et al. 1987).

The renal accumulation of macrophages expressing MRP8 and macrophages expressing MRP14 was reported to be associated with the inflammatory activity of glomerulonephritis (Hisano et al. 2001; Frosch et al. 2004). In addition, a few reports have examined the relation between the accumulation of macrophages expressing MRP8 and macrophages expressing MRP14 and IgAN (Hisano et al. 2001; Frosch et al. 2004). However, there have been no reports on relationship between the accumulation of macrophages expressing MRP8 and macrophages expressing MRP14 and the progression of IgAN.

Received January 22, 2009; revision accepted for publication March 25, 2009.

Correspondence: Yukihiko Kawasaki, 1 Hikariga-oka, Fukushima City, Fukushima 960-1295, Japan.

e-mail: kyuki@fmu.ac.jp 
To clarify the role of MRP8 and MRP14 in IgAN, we evaluated the renal accumulation of macrophages expressing MRP8 and macrophages expressing MRP14 in children with focal segmental IgAN.

\section{Subjects and Methods}

The study was performed at Fukushima Medical University Hospital. All patients or their parents gave their informed consent.

\section{Patients}

At the Department of Pediatrics of Fukushima Medical University School of Medicine, between January 2000 and December 2006, patients were eligible for the study if they had been biopsied and were newly diagnosed to have focal segmental IgAN with mild proteinuria and if the following criteria were satisfied: (1) diagnosis of IgAN based on the presence of $\operatorname{IgA}$ as the sole or predominant immunoglobulin in the glomerular mesangium in the absence of systemic disease, such as Henoch-Schoenlein purpura nephritis or systemic lupus erythematosus; (2) under 15 years of age as of the start of therapy and follow-up; and (3) no previous treatment with corticosteroids or immunosuppressive drugs, and (4) sufficient renal biopsy tissue available for histological evaluation (minimum of 10 glomeruli). The children were divided into two groups based on the prognosis; Favorable group, consisting of 11 children with normal urine and 6 children with minor urinary abnormalities at the time of their most recent examination, and Unfavorable group, consisting of 8 children with persistent nephropathy. The clinical features and pathological findings, including MRP8, MRP14, and $\alpha$-smooth muscle actin (SMA) staining, in both groups were analyzed retrospectively.

As to diffuse IgA nephropathy, we treated them with multiple combination therapy including prednisolone, mizoribine, warfarin, and dipyridamole. After therapy, all patients had normal (stage A) and minor urinary abnormalities stage (stage B) and none had active renal disease (stage C) and renal insufficiency (stage D). Thus, we were not able to divided two groups according to the prognosis of diffuse IgA nephropathy and excluded the patients with diffuse IgA nephropathy in our study.

\section{Definitions}

Hematuria was defined as a small amount (+) of hemoglobin on a dipstick test or more than five red blood cells per high-power microscopic field in a centrifuged specimen. Proteinuria was defined as a small amount of protein $(+)$ on a dipstick test or proteinuria greater than $5 \mathrm{mg} / \mathrm{m}^{2} /$ hour in a 24-hour urine sample. Mild proteinuria was defined as proteinuria less than $40 \mathrm{mg} / \mathrm{m}^{2} /$ hour in a 24 -hour urine sample.

The Schwartz formula was used to estimate creatinine clearance using the serum creatinine level and the patient's height. A low creatinine clearance was defined as an estimated glomerular filtration rate (GFR) of $60 \mathrm{~mL} / \mathrm{min} / 1.73 \mathrm{~m}^{2}$ of body surface area. Clinical outcome was graded according to the following stages: A, normal (no hypertension, urinary abnormality, or protein excretion and a normal plasma creatinine concentration); B, minor urinary abnormalities (proteinuria $<20 \mathrm{mg} / \mathrm{m}^{2} / \mathrm{h}$ with or without microscopic-recurrent macroscopic hematuria); C, active renal disease (proteinuria $>20 \mathrm{mg} / \mathrm{m}^{2} / \mathrm{h}$ and/or an elevated plasma creatinine level); and D, renal insufficiency (GFR below $60 \mathrm{ml} / \mathrm{min} / 1.73 \mathrm{~m}^{2}$ ).

\section{Pathology}

The first renal biopsy was performed before treatment in all 25 children, while the second renal biopsy was performed during the recovery phase in all the patients $(24.6 \pm 1.4$ months after the initiation of treatment). The mean numbers of glomeruli found in the first and second biopsy specimens were $19.2 \pm 7.2(10-31)$, and $22.1 \pm 7.4$ (15-33), respectively. The specimens were examined using light microscopy (LM) and immunofluorescence (IF) microscopy. The biopsy specimens were fixed in $12 \%$ neutral formalin, embedded in paraffin, cut into 2- to $3-\mu \mathrm{m}$-thick sections, and stained with hematoxylin and eosin or periodic acid-Schiff reagent.

The biopsy specimens were compared using a histological scoring system that was modified to determine activity index and chronicity index changes by the methods of previous reports (Kawasaki 2004). The activity index was determined as follows: mesangial proliferation (grades $0-3$, normal $=0$, slight $=1$, moderate $=2$, and severe $=3$ ), interstitial mononuclear cell infiltration (none $=0,1 \%-20 \%=1$, $21 \%-50 \%=2$, and $>50 \%=3$ ), and crescent formation $0-3$, according to the percentage of glomeruli involved (none $=0,1 \%-20 \%=1$, $21 \%-50 \%=2$, and $>50 \%=3$ ). The sum of these numbers comprised the activity score (maximum $=9$ ). The chronicity index was determined as follows: the numbers of glomeruli exhibiting fibrous crescents segmental sclerosis, or global sclerosis were counted and each scored as $0-3$ according to the percentage of glomeruli involved (none $=0,1 \%-20 \%=1,21 \%-50 \%=2$, and $>50 \%=3$ ); tubular atrophy and interstitial fibrosis were graded as 0-3. The sum of these numbers was the chronicity score (maximum $=12$ ).

The histological sections were reviewed by two independent investigators who were unaware of the patients' clinical data at the time of entry into the study.

Tissues for IF microscopy were immediately fixed in ornithine carbamoyltransferase compound and frozen at $-80^{\circ} \mathrm{C}$ until use. The IF staining results for $\mathrm{IgG}, \mathrm{IgA}, \mathrm{IgM}, \mathrm{C} 1 \mathrm{q}, \mathrm{C} 3, \mathrm{C} 4$ and fibrinogen were examined.

Macrophages and macrophage subclasses were detected immunohistochemically on serial paraffin sections using the enzyme-labeled indirect method. The primary antibodies used were mouse antihuman PG-M1 monoclonal antibody (CD68) (mAb; diluted 1 : 100; Dakopatts, Glostrup, Denmark) as a macrophage marker, mouse antihuman MRP14 monoclonal antibody (BMA, Augst, Switzerland) as a marker of acute-stage inflammatory macrophages, mouse anti-human MRP8 monoclonal antibody (BMA, Augst, Switzerland) as a marker of chronic-stage inflammatory macrophages, and mouse antihuman $\alpha$-SMA monoclonal antibody (mAb; 1 : 50; Dakopatts, Glostrup, Denmark). Peroxidase-conjugated rabbit anti-mouse IgG (diluted 1 : 100; Dakopatts) was used as the secondary antibody. Briefly, formalin-fixed paraffin-embedded sections $(3 \mu \mathrm{m})$ were deparaffinized and then treated with $0.1 \%$ trypsin solution (Difco Laboratories, Detroit, MI, USA) for CD68 staining. Then, endogenous peroxidase activity was blocked with $0.3 \% \mathrm{H}_{2} \mathrm{O}_{2}$ in methanol for $30 \mathrm{~min}$ at room temperature. After washing in phosphate-buffered saline (PBS), the sections were incubated overnight at $4^{\circ} \mathrm{C}$ with anti-human PG-M1 monoclonal antibody, mouse anti-human MRP8 monoclonal antibody, mouse antihuman MRP14 monoclonal antibody, and mouse antihuman $\alpha$-SMA monoclonal antibody (mAb; diluted 1: 50; Dakopatts, Glostrup, Denmark). The sections were then washed with PBS and flooded overnight at $4^{\circ} \mathrm{C}$ with secondary antibody. Finally, the sections were washed with PBS and then reacted in substitute medium containing 3, 3'-diaminobenzidine-tetrachloride (DAB) before hematoxylin 


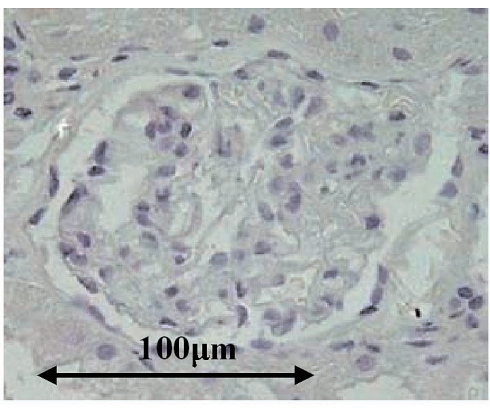

Score 0

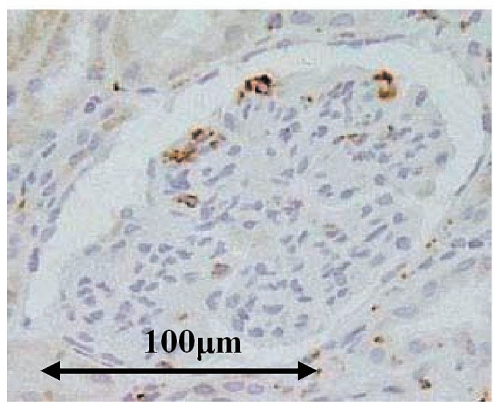

Score 2

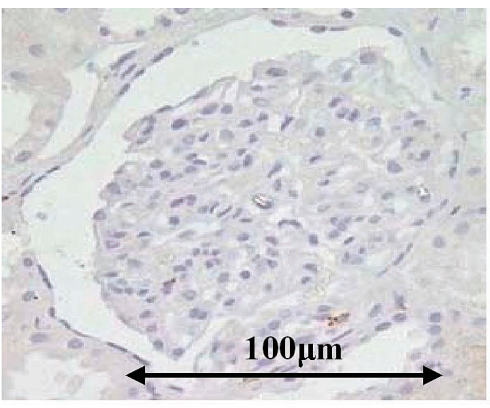

Score 1

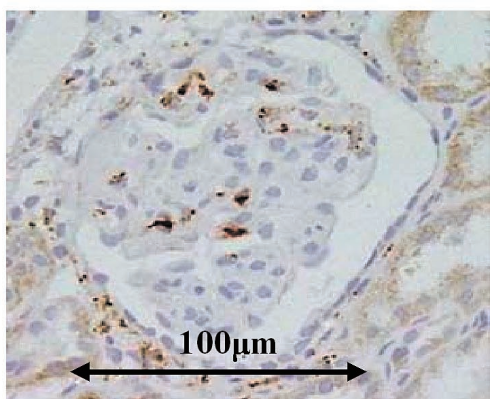

Score 3

Fig. 1. Scoring system for CD68 immunostaining in glomeruli.

(a) CD68 score 0: No CD68-positive cells are present in the glomerulus. (b) CD68 score 1: 1-5 CD68-positive cells are present in the glomerulus. (c) CD68 score 2: 5-10 CD68-positive cells are present in the glomerulus. (d) CD68 score 3: More than 10 CD68-positive cells are present in the glomerulus.

A

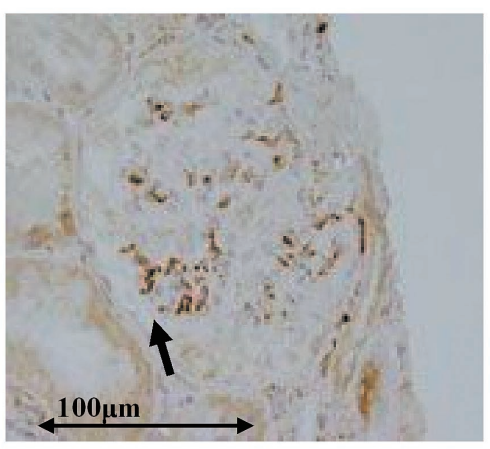

$\mathrm{C}$

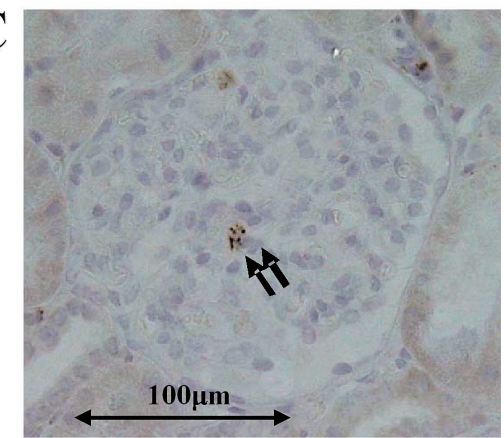

$\mathrm{B}$

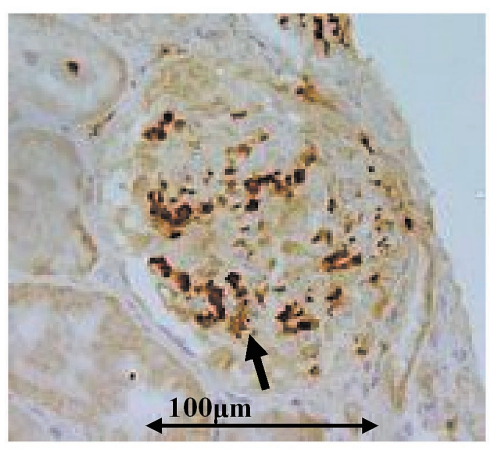

$\mathrm{D}$

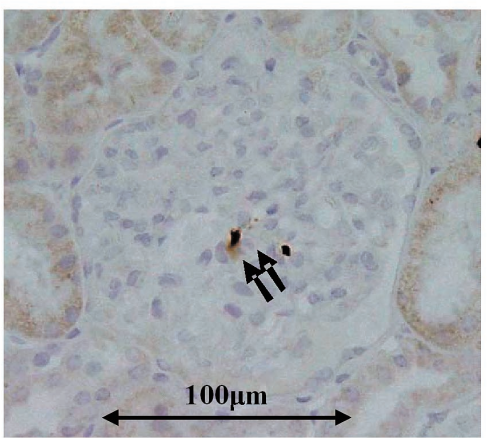

Fig. 2. Immunostaining for macrophages expressing MRP8 and macrophages expressing MRP14 in the glomeruli of biopsy specimens.

CD68-positive cells (A, C), MRP8-positive cells (B), and MRP14-positive cells (D) are shown. The single arrows point to an MRP8+CD68+ cell (macrophages expressing MRP8) in the glomeruli (A and B). The double arrows point to an MRP14+CD68+ cell (macrophages expressing MRP14) in the glomeruli (C and D). 

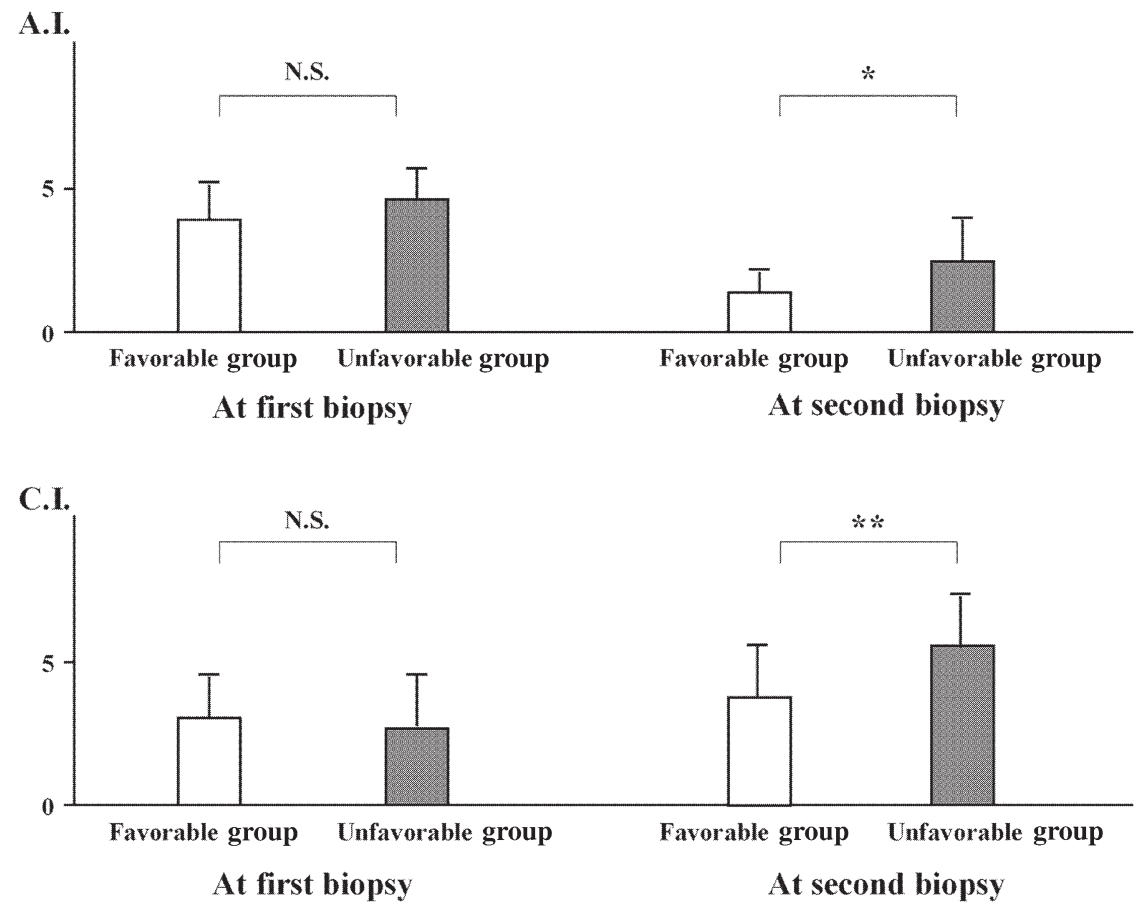

Fig. 3. Activity indexes and chronicity indexes of the first and second renal biopsies in Favorable group and Unfavorable group.

${ }^{*} p<0.05 * * P<0.01$ N.S., not significant.

nuclear staining. As a negative control, the primary antibody was replaced using similar immunoglobulins.

\section{Immunohistochemical scoring}

CD68-positive (CD68+) cells within the glomeruli were counted as macrophages, and MRP8 and CD68 double-positive (MRP8+ CD68+) cells, MRP14 and CD68 double-positive (MRP14+CD68+) cells (Figs. 1 and 2), and $\alpha$-SMA-positive cells within the glomeruli were counted. $\alpha$-SMA is the actin isoform that predominates within vascular smooth-muscle cells. Myofibroblasts express cytoplasmic $\alpha$-SMA, which plays an important role in fibrogenesis. Alpers et al (1992) indicated that mesangial cells undergo phenotypic change and express $\alpha$-SMA in patients with mesangioproliferative glomerulopathies. The numbers of positive cells were counted in all the glomeruli in the cross-serial sections of the biopsy specimens.

\section{Therapeutic interventions}

Children were treated with a combination of prednisolone, warfarin, and dipyridamole (PWD). Prednisolone was given orally at a dose of $1 \mathrm{mg} / \mathrm{kg}$ body weight per day in three divided doses, with a maximum dosage of $60 \mathrm{mg} /$ day, for 2 weeks, followed by $0.75 \mathrm{mg} / \mathrm{kg}$ per day for 2 weeks, $0.5 \mathrm{mg} / \mathrm{kg}$ per day for 4 weeks, $0.25 \mathrm{mg} / \mathrm{kg}$ per day for 4 weeks, and $0.5 \mathrm{mg} / \mathrm{kg}$ per 2 days for 21 months. Warfarin was given orally at a dose of $1-2 \mathrm{mg} /$ day in a single morning dose that was sufficient to maintain thrombotest results at 30\% to $40 \%$ for 24 months. Dipyridamole was given orally at a dose of $5 \mathrm{mg} / \mathrm{kg}$ body weight per day in three divided doses, with a maximum total dosage of $400 \mathrm{mg} /$ day, for 24 months.

\section{Statistics}

Data are expressed as the mean values \pm S.D. The statistical analysis was performed using a Macintosh computer with a software package for statistical analysis (Version 4 of Stat View, Abacus Concepts, Berkeley, Calif., USA). Differences in the laboratory findings of the two groups were assessed using the Mann-Whitney rank sum test or contingency tables (chi square test). Correlations were evaluated using the Fisher $r$-test.

\section{Results}

Baseline characteristics and laboratory findings at the time of the first and second renal biopsies

Age at onset and duration of follow-up from the initial therapy were $11.5 \pm 2.7$ and $4.3 \pm 1.3$ years, respectively, in Favorable group and $12.1 \pm 3.7$ and $4.6 \pm 1.1$ years in Unfavorable group; the male to female ratios were $9: 8$ and $4: 4$ in Favorable and Unfavorable groups, respectively (Table 1). Duration from onset to renal biopsy and duration from the first renal biopsy to the second biopsy were $5.7 \pm$ 4.8 and $24.6 \pm 1.3$ months in Favorable group and $5.4 \pm 5.0$ and $24.4 \pm 1.4$ months in Unfavorable group, respectively.

The urinary protein excretion levels, the serum albumin levels, the incidence of hematuria, the serum creatinine values, and the serum IgA values were similar in Favorable group and Unfavorable group.

At the time of the second renal biopsy (at $24.5 \pm 1.3$ months after the first renal biopsy), the urinary protein excretion, the incidence of hematuria, and the serum IgA values in Unfavorable group were higher than those in Favorable group (Table 2). The serum creatinine values were similar in Favorable group and Unfavorable group. 
Table 1. Patient characteristics in Favorable group and Unfavorable group.

\begin{tabular}{lcc}
\hline & $\begin{array}{c}\text { Favorable group } \\
(n=17)\end{array}$ & $\begin{array}{c}\text { Unfavorable group } \\
(n=8)\end{array}$ \\
\hline Age at onset (years) & $11.5 \pm 2.7$ & $12.1 \pm 3.7$ \\
Duration from onset of symptoms to biopsy (months) & $5.7 \pm 4.8$ & $5.4 \pm 5.0$ \\
Gender (male : female) & $9: 8$ & $4: 4$ \\
Time from initial therapy to end of study (y) & $4.3 \pm 1.3$ & $4.6 \pm 1.1$ \\
Time from initial biopsy to second biopsy & $24.6 \pm 1.3$ & $24.4 \pm 1.4$ \\
\hline
\end{tabular}

Table 2. Laboratory data at the time of the first and second biopsies in Favorable group and Unfavorable group.

\begin{tabular}{|c|c|c|c|c|}
\hline & \multicolumn{2}{|c|}{ First renal biopsy } & \multicolumn{2}{|c|}{ Second renal biopsy } \\
\hline & $\begin{array}{l}\text { Favorable group } \\
\quad(n=17)\end{array}$ & $\begin{array}{l}\text { Unfavorable group } \\
\qquad(n=8)\end{array}$ & $\begin{array}{l}\text { Favorable group } \\
\quad(n=17)\end{array}$ & $\begin{array}{l}\text { Unfavorable group } \\
\qquad(n=8)\end{array}$ \\
\hline Urinary protein excretion $\left(\mathrm{mg} / \mathrm{m}^{2} / \mathrm{h}\right)$ & $18.6 \pm 13.2$ & $20.4 \pm 10.6$ & $0.8 \pm 1.2^{\mathrm{a}}$ & $8.3 \pm 5.0^{\mathrm{a}}$ \\
\hline Freguency of hematuria (\%) & 100 & 100 & $23.5^{\mathrm{b}}$ & $100^{\mathrm{b}}$ \\
\hline Serum albumin $(\mathrm{g} / \mathrm{L})$ & $42 \pm 7$ & $40 \pm 6$ & $44 \pm 4$ & $42 \pm 3$ \\
\hline Serum creatinine $(\mu \mathrm{mol} / \mathrm{L})$ & $48.6 \pm 13.3$ & $49.5 \pm 11.5$ & $42.4 \pm 9.7$ & $45.1 \pm 8.8$ \\
\hline Serum IgA $(\mathrm{mg} / \mathrm{dl})$ & $262.4 \pm 80.3^{\mathrm{c}}$ & $259.8 \pm 77.5$ & $214.1 \pm 77.9^{c}$ & $277 \pm 85.4$ \\
\hline
\end{tabular}

$\mathrm{a}, \mathrm{b}, \mathrm{c}: p<0.01$

Table 3. The numbers of macrophages expressing MRP8 or MRP14 and mesangial cells expressing $\alpha$-SMA.

\begin{tabular}{|c|c|c|c|c|}
\hline & & Favorable group & Unfavorable group & $P$ \\
\hline \multirow[t]{3}{*}{ First Biopsy } & Glomerular macrophages expressing MRP8 & $6.3 \pm 2.2^{\mathrm{a}}$ & $7.8 \pm 3.5$ & NS \\
\hline & Glomerular macrophages expressing MRP14 & $1.7 \pm 1.4^{\mathrm{b}}$ & $2.5 \pm 1.5^{\mathrm{c}}$ & NS \\
\hline & Mesangial cells expressing $\alpha$-SMA & $5.6 \pm 2.0^{\mathrm{d}}$ & $6.5 \pm 1.3^{\mathrm{e}}$ & NS \\
\hline \multirow[t]{3}{*}{ Second Biopsy } & Glomerular macrophages expressing MRP8 & $1.7 \pm 1.2^{\mathrm{a}}$ & $5.9 \pm 1.6$ & $<0.01$ \\
\hline & Glomerular macrophages expressing MRP14 & $0.4 \pm 0.6^{b}$ & $0.5 \pm 0.5^{\mathrm{c}}$ & NS \\
\hline & Mesangial cells expressing $\alpha$-SMA & $2.7 \pm 1.2^{\mathrm{d}}$ & $8.3 \pm 2.9^{\mathrm{e}}$ & $<0.01$ \\
\hline
\end{tabular}

Shown are the mean numbers of macrophages and mesangial cells expressing $\alpha$-SMA in Favorable group and Unfavorable group.

NS, not significant.

$\mathrm{a}, \mathrm{b}, \mathrm{c}, \mathrm{d}: p<0.01, \mathrm{e}: p<0.05$

Glomerular accumulation of macrophages expressing MRP8 and mesangial cells expressing $\alpha$-SMA in Unfavorable group

In Favorable group, the mean numbers of glomerular macrophages expressing MRP8, macrophages expressing MRP14, and mesangial cells expressing $\alpha$-SMA were lower in the second biopsy specimens than those of the first biopsy specimens (Table 3). In Unfavorable group, the mean numbers of glomerular macrophages expressing MRP8 of the first and second biopsy specimens were similar. The mean numbers of glomerular mesangial cells expressing $\alpha$-SMA of the second biopsy specimens were higher than those of the first biopsy specimens.

In the first biopsy specimens, there was no difference in the mean numbers of glomerular macrophages expressing MRP8, macrophages expressing MRP14, and mesangial cells expressing $\alpha$-SMA between Favorable group and Unfavorable group (Table 3). In the second biopsy speci- mens, the mean numbers of glomerular macrophages expressing MRP8 and mesangial cells expressing $\alpha$-SMA were higher in Unfavorable group than those in Favorable group.

Comparison of activity index and chronicity index in the first and second biopsy specimens

The activity indexes in Favorable group and Unfavorable group were lower in the second biopsy specimens than in the first biopsy specimens $(1.1 \pm 0.8$ vs $4.1 \pm 1.4$ in Favorable group and $2.4 \pm 1.5$ vs $4.5 \pm 1.1$ in Unfavorable group, respectively), while the chronicity indexes in Unfavorable group were higher in the second biopsy specimens than in the first biopsy specimens $(5.7 \pm 1.7$ vs $2.5 \pm$ $1.5)$. 
Table 4. Mesangial cells expressing $\alpha$-SMA and chronicity indexes in Group M and Group L.

\begin{tabular}{lcccccc}
\hline & \multicolumn{2}{c}{ First biopsy } & & \multicolumn{2}{c}{ Second biopsy } \\
\cline { 2 - 3 } \cline { 5 - 6 } & Group M & Group L & & Group M & Group L \\
\hline Mean numbers of glomerular $\alpha$-SMA-positive cells & $7.6 \pm 2.2^{\mathrm{a}}$ & $3.6 \pm 1.0^{\mathrm{a}}$ & & $6.5 \pm 1.4^{\mathrm{b}}$ & $1.9 \pm 1.3^{\mathrm{b}}$ \\
Chronicity indexes & $2.9 \pm 2.0$ & $1.6 \pm 1.3$ & & $5.3 \pm 1.8^{\mathrm{c}}$ & $2.7 \pm 1.0^{\mathrm{c}}$ \\
\hline
\end{tabular}

All parameters are expressed as mean \pm S.D.

Significant differences between Group M and Group L: a, $p<0.01 ; \mathrm{b}, p<0.01$; and c, $p<0.01$.

Mesangial cells expressing $\alpha-S M A$ and chronicity
indexes of Groups with accumulated macrophages
expressing MRP8
Twenty-five patients were divided into two groups according to the numbers of glomerular macrophages expressing MRP8 (Table 4). Group M consisted of 8 patients with more macrophages expressing MRP8 (the mean numbers of glomerular macrophages expressing MRP8 more than 6) and Group L consisted of 17 patients with less macrophages expressing MRP8 (the mean numbers of glomerular macrophages expressing MRP8 less 6). In the first biopsy, the mean numbers of glomerular mesangial cells expressing $\alpha$-SMA were higher in Group M than in Group L, while the chronicity indexes of these two groups were similar. In the second biopsy, the mean numbers of glomerular mesangial cells expressing $\alpha$-SMA and the chronicity indexes were higher in Groups $M$ than in Group L.

\section{Discussion}

The results of our study showed that the renal accumulation of macrophages expressing MRP8 and mesangial cells expressing $\alpha$-SMA in Unfavorable group were higher than those in Favorable group in the second biopsy specimens, and the renal accumulation of mesangial cells expressing $\alpha$-SMA and chronicity indexes were higher in children with much macrophages expressing MRP8 than in children with less macrophages expressing MRP8 in the second biopsy.

Numerous studies on IgAN have tried to identify prognostic markers both clinically and histopathologically. Analyses of the prognostic value of morphological lesions have shown that advanced glomerular and tubulointerstitial lesions are the strongest predictors of IgAN progression (Droz 1976; Hogg et al. 1994; Chida et al. 1985). The current study emphasizes that tubulointerstitial lesions predict the outcome of adult IgAN (Andreoli et al. 1989; Nagata et al. 1995; Nozawa et al. 2005). Our institute regards chronic tubulointerstitial damage to be a determinant of the prognosis of childhood IgAN (Nozawa et al. 2005).

The association of macrophages in interstitial lesions characterized by renal dysfunction and histological damage, causing renal injury, has recently been reported. Furthermore, several reports have discussed the roles of macrophage subclasses, such as macrophages expressing MRP8 and macrophages expressing MRP14, in inflammatory dis- ease (Zwadlo et al. 1985; Odink et al. 1987; Roth et al. 1992; Brurkhardt et al. 1995; Roth et al. 2001). MRP8 and MRP14 are two calcium-binding proteins of the S100 family, which has become one of the largest known subfamilies of EF-hand proteins. S100 proteins play a role in cell differentiation, cell cycle progression, the regulation of kinase activities, and cytoskeletal-membrane interactions. Macrophages expressing MRP14 are generally thought to be associated with more acute inflammation, whereas macrophages expressing MRP8 occur more frequently in chronic lesions.

Regarding renal disease, Burkhardt et al. (1995) showed that the intensity of the MRP8/MRP14-positive infiltrate is a prognostic factor for the course and outcome of acute renal allograft rejection, and Frosch et al. (2004) found that MRP8/MRP14-expressing monocytes were prevalent in highly proliferative forms of glomerulonephritis, such as systemic lupus erythematosus glomerulonephritis, and extracapillary glomerulonephritis. We previously showed that the kidneys of patients with membranoproliferative glomerulonephritis (MPGN) with persistent nephropathy and renal insufficiency at the time of their most recent follow-up examination exhibited strong glomerular and interstitial MRP8-positive CD68-positive double staining (Kawasaki et al. 2005). In addition, glomerular and interstitial MRP8-positive CD68-positive double staining in the first biopsy specimens was correlated with the chronicity indexes in the second biopsy specimens (Kawasaki et al. 2005).

Regarding the renal accumulation of macrophages expressing MRP8 in IgAN, the mean numbers of glomerular macrophages expressing MRP8 and mesangial cells expressing $\alpha$-SMA in Unfavorable Group were higher than those in Favorable Group in the second biopsy specimens. In addition, the mean numbers of glomerular and the chronicity indexes were higher in children with much macrophages expressing MRP8 than in children with less macrophages expressing MRP8 in their second biopsy specimens. These findings suggest that the renal accumulation of macrophages expressing MRP8 and mesangial cells expressing $\alpha$-SMA were associated with chronicity indexes and the renal prognosis. Thus, the renal macrophages expressing MRP8 might reflect a predilection for chronic inflammation and a poor prognosis in children with IgAN.

As to the association with MRP8 and renal injury, there have recently been some reports concerning with novel 
molecular mechanism underlying chronic processes of IgAN. Vogl et al. (2007) reported that MRP8 has been shown to interact with and to activate Toll-like receptor 4 (TLR4). TLR, sensors in the innate immune system, have been best characterized as a system to recognize danger signals to the host arising from pathogen-associated molecular patterns. Banas et al. (2008) showed that TLR4 is constitutively expressed by podocytes and is upregulated in mouse models of cryoglobulinemic membranoproliferative glomerulonephritis, where it may mediate glomerular injury by modulating expression of chemokines. Furthermore, TLR4 has been demonstrated to play an important role in antibody-mediated glomerulonephritis (Brown et al. 2007), and development of fibrosis (Seki et al. 2007).

The present study was relatively small, and we are now attempting to confirm the above findings by conducting a large study examining the correlation between renal macrophages expressing MRP8 and the long-term outcome of children with focal segmental IgAN.

In conclusion, our results suggest that renal macrophages expressing MRP8 may be involved in the progression of sclerotic changes in children with IgAN.

\section{References}

Andreoli, S.P. \& Bergstein, J.M. (1989) Treatment of severe IgA nephropathy in children. Pediatr. Nephrol., 3, 248-253.

Alpers, C.E., Hudkins, K.L., Gown, A.M. \& Jhonson, R.J. (1992) Enhanced expression of muscle-specific actin in glomerulonephritis. Kidney Int., 41, 1134-1142.

Berger J. \& Hinglais N. (1968) Les depots intercapillareis d'IgAIgG. J. Urol. Nephrol., 74, 694-695.

Banas, M.C., Banas, B., Hudkins, K.L., Wietecha, T.A., Iyoda, M., Bock, E., Hauser, P., Pippin, J.W., Shankland S.J., Smith, K.D., Stoelcker, B., Liu, G., Grone, H., Kramer, B.K. \& Alpers, C.E. (2008) TLR4 links podocytes with the innate immune system to mediate glomerular injury. J. Am. Soc. Nephrol., 19, 704-713.

Brown, H.J., Lock, H.R., Wolfs, T.G.A.M., Buurman, W.A., Sacks, S.H. \& Robson, M.G. (2007) Toll-like receptor 4 ligation on intrinsic renal cells contributes to the induction of antibodymediated glomerulonephritis via CXCL1 and CXCL2. J. Am. Soc. Nephrol., 18, 1732-1739.

Burkhardt, K., Bosnecker, A., Hillebrand, G., Hofmann, G.O., Schneeberger, H., Burmeister, G., Land, W. \& Gurland, H.J. (1995) MRP8/14-positive macrophages as early acute cellular rejection markers, and soluble MRP8/14 and increased expression of adhesion molecules following renal transplantation. Transplant. Proc., 27, 890-891.

Chida, Y., Tomura, S. \& Takeuchi, J. (1985) Renal survival rate of IgA nephropathy. Nephron, 40, 189-194.

Coppo, R. \& Amore, A. (2008) IgA Nephropathy. Comprehensive Pediatric Nephrology, First ed., edited by Geary DF \&
Schaefer F. MOSBY ELSEVIER, Philadelphia, PA, pp. 291-300.

Droz, D. (1976) Natural history of primary glomerulonephritis with mesangial deposits of IgA. Contrib. Nephrol., 2, 150-157.

Frosch, M., Vogl, T., Waldherr, R., Sorg, C., Sunderkotter, C. \& Roth, J. (2004) Expression of MRP8 and MRP14 by macrophages is a marker for severe forms of glomerulonephritis. $J$. Leukoc. Biol., 75, 198-206.

Hisano, S., Sasatomi, Y., Kiyoshi, Y. \& Takebayashi, S. (2001) Macrophage subclasses and proliferation in childhood IgA glomerulonephritis. Am. J. Kidney Dis., 37, 712-719.

Hogg, R.J., Silvia, F., Wyatt, R., Reisch, J.S., Argyle, J.C. \& Savino, D.A. (1994) Prognostic indicators in children with IgA nephropathy-report of the Southwest Pediatric Nephrology Study Group. Pediatr. Nephrol., 8, 15-20.

Kawasaki, Y., Hosoya, M., Onishi, N., Takahashi, A., Isome, M., Nozawa, R. \& Suzuki, H. (2004) Efficacy of multidrug therapy combined with mizoribine in children with diffuse $\operatorname{IgA}$ nephropathy in comparison with multidrug therapy without mizoribine and with methylprednisolone pulse therapy. Am. $J$. Nephrol., 24, 576-581.

Kawasaki, Y., Hosoya, M., Takahashi, A., Isome, M., Tanji, M. \& Suzuki, H. (2005) Myeloid-related protein 8 expression on macrophages is a useful prognostic marker for renal dysfunction in children with MPGN type 1. Am. J. Kidney Dis., 45, 510-518.

Nagata, M., Akioka, Y., Tsunoda, Y., Komatsu, Y., Kawaguchi, H. \& Ito, K. (1995) Macrophages in childhood IgA nephropathy. Kidney Int., 48, 527-535.

Nozawa, R., Suzuki, J., Takahashi, A., Isome, M., Kawasaki, Y., Suzuki, S. \& Suzuki, H. (2005) Clinicopathological features and the prognosis of IgA nephropathy in Japanese children on long-term observation. Clin. Nephrol., 64, 171-179.

Odink, K., Cerletti, N., Bruggen, J., Clerc, R.G., Tarcsay, L., Zwadlo, G., Gerhards, G., Schlegel, R. \& Sorg, C. (1987) Two calcium-binding proteins in infiltrate macrophages of rheumatoid arthritis. Nature, 330, $80-82$.

Roth, J., Goebeler, M. \& Sorg, C. (2001) S100A8 and S100A9 in inflammatory diseases. Lancet, 357, 1041.

Roth, J., Teigelkamp, S., Wike, M., Grun, L., Tnmmler, B. \& Sorg, C. (1992) Complex pattern of the myelo-monocytic differentiation antigens MRP8 and MRP14 during chronic airway inflammation. Immunobiology, 186, 304-314.

Seki, E., Minicis, S.D., Osterreicher, C.H., Kluwe, J., Osawa, Y., Brenner, D.A. \& Schwabe, R.F. (2007) TLR4 enhances TGF$\beta$ signaling and hepatic fibrosis. Nature Medicine, 13, 1324-1332.

Vog1, T., Tenbrock, K., Ludwig, S., Leukert, N., Ehrhardt, C., Zoelen, MAD., Nacken, W., Foell, D., Poll, T., Sorg, C. \& Roth, J. (2007) Mrp8 and Mrp14 are endogenous activators of Toll-like receptor 4, promoting lethal, endotoxin-induced shock. Nature Medicine, 13, 1042-1049.

Zwadlo, G., Brocker, E.B., von Bassewitz, D.B., Feige, U. \& Sorg, C. (1985) A monoclonal antibody to a differentiation antigen present on mature human macrophages and absent from monocytes. J. Immunol., 134, 1487-1492. 